[ FAUSTO VIANA | ROSANE MUNIZ]

Fausto Viana é figurinista, cenógrafo e pesquisador. É mestre, doutor e livre-docente pela ECA-USP e anda pelo mundo unindo duas paixões: a indumentária e a museologia. Deve concluir em breve seu doutoramento em museologia na Universidade Lusófona. Visite o blog: tramasdocafecomleite.wordpress.com

E-mail: faustoviana@uol.com.br

Rosane Muniz é jornalista, atriz e pesquisadora. Autora do livro Vestindo os nus - o figurino em cena (Senac Rio, 2004) e mestra em Artes Cênicas (ECA-USP), mantém o blog www.vestindoacena.com E-mail: romuniz@gmail.com

\title{
De quando o Conde Drácula conheceu a baiana
}

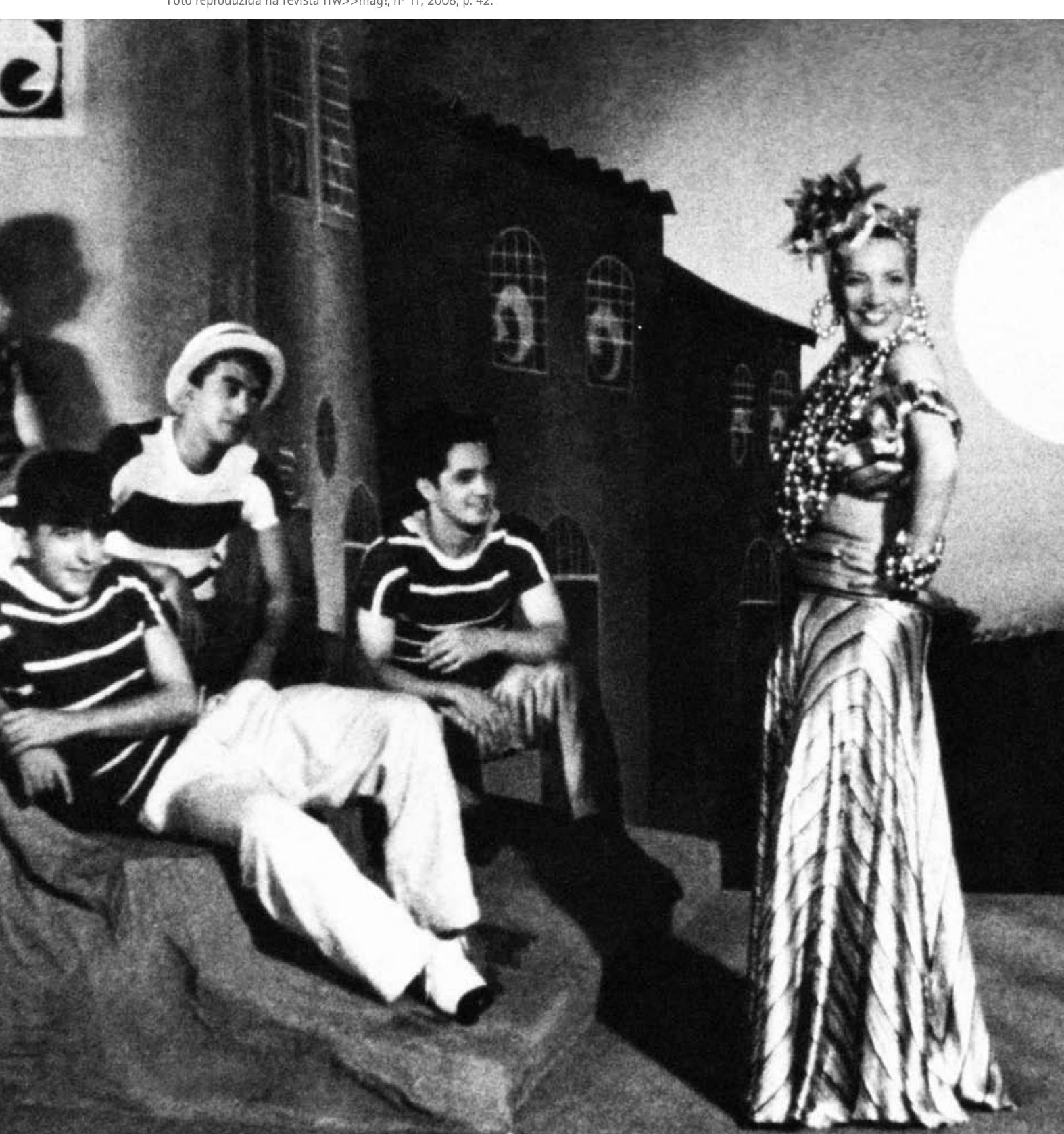


Nossa coluna desta edição é resultado de uma guerra de bastidores.

0 marco da batalha foi dado pela Romênia, que nos convidou a palestrar no encontro anual do Grupo de Trabalho de Figurino da Organização Internacional de Cenógrafos, Técnicos e Arquitetos de Teatro (OISTAT) sobre "A Influência do Traje Popular (que nós aqui chamamos de regional) no Figurino Teatral".' Seria preciso levar dois trajes para uma Parada de Figurinos, além de fotos para uma exposição e uma apresentação para o simpósio.

Estava armado o armistício entre estes dois colunistas: qual seria o traje regional brasileiro mais característico e representativo de nossa cultura?

Na Romênia, com um território que cabe inteiro só no Estado de Minas Gerais e tem, entre outros, "apelos" como a Transilvânia e a maior comunidade de ciganos no mundo, a escolha deve ter sido mais fácil. Aqui, tivemos que pensar nos trajes regionais do gaúcho, do cangaceiro, do caipira, dos vaqueiros... Sobravam ainda os bordados mineiros, as vestimentas especiais das festas de Folia de Reis, Maracatu, Bumba Meu Boi, Corpus Christi, Congo, Reisado, Congada, Caiapó e Cavalhada. Mas estes já entravam no quesito traje folclórico.

Como um barril de pólvora, entra a indumentária da baiana na contenda.

A vestimenta da baiana, feita de algodão bordado, apesar de também ser produzida em seda, linho e alguns outros materiais, chegou ao Brasil já no final do século XVIII2. E de lá para cá foi ganhando cada vez mais status.

Agora, classificar a veste da baiana é um embate histórico ${ }^{3}$. Pode ser eclesiástico (religioso), usado em cerimônias especiais? Sim. Pode ser vestimenta profissional, de trabalho, como o das vendedoras de acarajé? Pode. Pode ser fantasia de carnaval, e portanto traje de folguedo? Também!

Afinal, o que é que a baiana tem?

Tem uma roupa regional que pode não ser comum ao país como um todo - porque, vá lá, esta terra é enorme -, mas certamente é uma das mais famosas entre as populares brasileiras.

Assinado este primeiro acordo de paz entre os colunistas, vem Mariza Lira, folclorista, escritora e compositora e diz que "a baiana não é propriamente um traje típico da Bahia e muito menos do Brasil, pois não se veem mulheres vestidas como tal em Salvador ou no interior do Estado, já que este traje só foi usado nas ruas pelas negras doceiras ou vendedoras de acarajé". Mas e as roupas coloridas? E as disputas entre negras e brancas? Afinal, desde que chegou com os escravos, gradativamente o traje foi sendo usado também nos terreiros, nas cerimônias religiosas e até nos passeios do século XIX.

0 problema neste ponto de vista é que a roupa da baiana não pode ser considerada somente a "clássica" branca. A transformação que as mulheres da Bahia deram ao traje, transformando-o em afro-brasileiro, com seus multicoloridos e balangandãs, deve ser levada em conta.

Abel Cardoso Junior, produtor musical, lembra oportunamente que, dentro e fora do Brasil, a "baiana" terminou sendo considerada nosso traje nacional típico, por causa de Carmen Miranda. Vêm daí muitos preconceitos e interpretações distintas dessa indumentária, que a cantora popularizou em uma versão estilizada.

Dorival Caymmi declarava que escreveu a letra da música 0 que é que a baiana tem? (se você não conhece, shame on you! Ouça JÁ em qualquer site de músicas na internet!) pensando "naquelas mulheres que se vestiam ao rigor da moda e que saíam à rua para saracotear nos dias de festa". Mas também se inspirou na roupa original: 'Tenho um tio antiquário e como sempre andei 'fuçando' velharias e descobri uma estampa velhíssima onde se viam baianas autênticas com 'balangandãs' e outros enfeites desconhecidos. Querendo divulgar como eram minhas patrícias do passado, criei o samba". ${ }^{5}$ Em outra declaração, Caymmi complementou: "Em verdade, balangandãs é uma penca de pequenos fetiches negros, feitos em prata e ouro, usada pelas baianas de 'partido alto' nas grandes festas populares da Bahia (...). A palavra, desenterrada pelo samba, virou quase sinônimo de coisa nacional".

A música entrou na trilha do filme Banana da terra (1938) e gastaram-se somente cinco dólares por todos os balangandãs. Nascia a imagem de baiana de Carmen Miranda, com saia rodada e sem as anáguas, para que ela pudesse dançar livremente.

Mais tarde, parte da renovação da imagem de Carmen Miranda seria dada por influência do ilustrador da revista 0 Cruzeiro, Alceu Penna: "0 desenhista faz uma 
série de sugestões para 'renovar' o guarda-roupa da cantora. Ele conta que adicionou 'inclusive saias multicolores, os turbantes fantásticos e os sapatões de solas grossas. Desenhei também as suas fantasias quando ela foi para Hollywood com o Bando da Lua'". É este figurino superestilizado, criado para shows, que ficará popularizado e muito conhecido, inclusive internacionalmente, como um traje típico nacional.

É importante lembrar também que, segundo Ruy Castro ${ }^{8}$, nas revistas musicais brasileiras, havia sempre números de "baianas", vestidas de forma simples e tradicional. Em 1892, sobe ao palco Pepa Ruiz, vestida como a primeira baiana estilizada da história. Muitas outras cantoras de cassino usaram esses trajes em diversos espetáculos de teatro e no cinema antes da versão famosa de Carmen Miranda.

0 assunto é tema para várias pesquisas, mas vamos pensar brevemente em suas diferentes vertentes: religiosa, uniforme profissional e fantasia. Será que a roupa da baiana pode mesmo ser considerada o verdadeiro traje típico nacional?

\section{Religião}

A veste ritualística da baiana surgiu no candomblé, que reuniu várias religiões negras de origem africana e crenças indígenas brasileiras. Como culto organizado tem como provável marco de início a fundação do Candomblé do Engenho Novo, por volta de 1830, na cidade do Salvador.

Nesse sincretismo religioso, os negros só puderam exibir os trajes usados nos rituais africanos a partir do século XIX. A roupa do orixá Oxalá é a única que é toda branca, como a da baiana mais tradicional. Todas as filhas do terreiro trajam branco para ir às cerimônias, mas os orixás de cada uma só vestem branco em cultos especiais em homenagem a Oxalá. Fora isso, cada divindade possui seu traje característico, que nada tem a ver com o de baiana, o qual tem demandado estudos especificos.

Apenas para completar o exemplo, o traje de 0xalá é composto por calça, anáguas e "quebras-goma", saia, ojá (pano amarrado na cintura e na cabeça), camisu e pano da costa.

\section{Uniforme profissional}

A versão "uniforme" do traje de baiana advém da religião. 0 bolinho característico do candomblé, o acarajé, servia como oferenda para as divindades Xangô e lansã. No período do Brasil Colônia, passou a ser vendido nas ruas em tabuleiros que as escravas equilibravam sobre suas cabeças. "Estas mulheres eram obrigadas a vender as iguarias do candomblé para comprar a alforria do marido e filhos e conseguir sustento para a família após a abolição da escravatura. Mesmo depois que

Negras vestidas de branco e com o traje de baiana na Festa de Nossa Senhora do Rosário, em 1865. Foto de Christiano Jr.

Fonte: LAGO, B. C. do; LAGO, P. C. do. Os fotógrafos do Império. Rio de Janeiro: Capivara, 2005, p. 130.

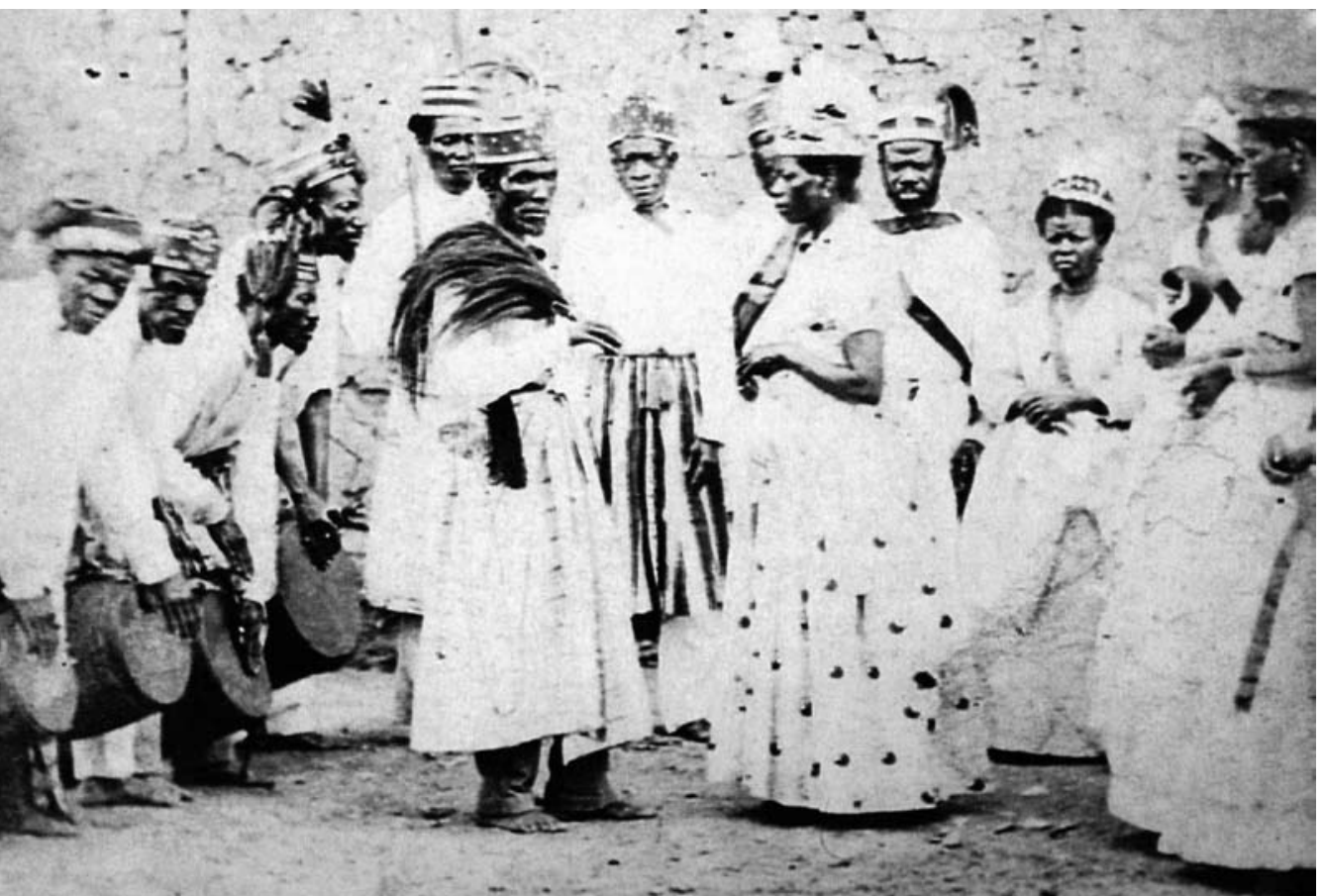


passou a ser vendido, o acarajé ainda é considerado, pelas baianas, como uma comida sagrada". As únicas pessoas autorizadas a vender o bolinho eram as filhas de lansã e Xangô, mas hoje existem mulheres de todas as religiões trabalhando como baianas vendedoras de acarajé.

Com a disseminação da religião evangélica, polêmicas sobre usar ou não a roupa de baiana são constantes. Por esse motivo, e também para controlar a qualidade do quitute, foi criado até um estatuto (a atividade das baianas passou a ser regulamentada pelo decreto municipal 12.175/1998 e portarias subsequentes), definindo uma padronização da indumentária e do tabuleiro, e há reuniões constantes na Associação das Baianas de Acarajé e Mingau da Bahia (Abam).

A vendedora de acarajé Rose $^{10}$ aprendeu a cozinhar a iguaria com a mãe e representou o Rio de Janeiro na última reunião da Associação, em novembro de 2009, em Salvador. "0 uso da indumentária está no estatuto, quem não usá-la terá sua licença cassada. Se a pessoa confunde uma tradição - que já tornou o acarajé patrimônio imaterial da humanidade - com a prática de sua religião, deve desistir da profissão. Eu me sinto representando a minha terra, minha cultura". Porém, o quitute está diretamente ligado à tradição secular: há muitas baianas que não pegam nos materiais sem antes tomar um "banho de axé" (banho de folhas). Hoje, além das mulheres, também é possível encontrar homens fazendo acarajé.

A roupa "clássica" das baianas compõe-se de torço, bata, pano da costa, saia rodada e adornos, como colares, pulseiras, brincos de ouro, prata ou coral. As saias rodadas, estampadas em cores vivas, trazem muitas anáguas rendadas, engomadas para dar a roda. Usam os famosos balangandãs ou berenguendéns, que são muitos colares coloridos. 0 pano da costa, um pano retangular de dois metros por cinquenta centímetros, é tradicionalmente branco ou bicolor, podendo ser listrado ou em madras e bordados ou com aplicações em rendas. As batas são blusas de renda folgadas. As baianas ainda calçam chinelas ou calçados baixos, também enfeitados, e usam turbantes (torços), brancos ou coloridos.

\section{Fantasia}

Quando Carmen Miranda filmou sua primeira aparição vestida com sua versão da veste de baiana, a França inspirava o Brasil na moda. 0 traje não era muito bem-visto, já que era feito de chita e, conforme se falava, correspondia à ralé. Com a criação para Carmen, a roupa de baiana começou a ser usada também como fantasia de carnaval.

As roupas que a cantora usava eram bastante pesadas. A saia que vestiu no filme Copacabana, por exemplo, pesava 12 quilos. Já nos carnavais, os trajes apresentavam versões mais leves, mas passaram a pesar mais de 20 quilos, quando usados na avenida do samba pelas escolas de samba. Tia Noêmia"1 , primeira baiana da União da llha e coordenadora da ala das baianas na escola, acredita que "as mulheres estão desistindo de desfilar devido ao peso das fantasias e também por se tratarem de senhoras com mais idade". No mundo do samba, Tia Noêmia possui muitas recordações: "Lembro-me de uma vez que não chegaram as metades dos chapéus das baianas. Decidimos jogar tudo fora e desfilar na avenida sem nada na cabeça". Apesar do amor à ala e à tradição, o que importa mais é cumprir com as ordens para não perder pontos na competição.

Por incrivel que pareça, a ala de baianas, na década de 1930, era formada quase exclusivamente por homens que saiam nas laterais das escolas portando navalhas presas às pernas para defenderem as agremiações em caso de brigas. Não se sabe bem ao certo o porquê, mas provavelmente em homenagem a Oxalá, que é alheio a briga e violência e prima pela ordem e pureza. 
Na época em que o samba ainda era marginalizado, as "tias do samba" abrigavam os sambistas em suas casas. Foi só no biênio 1960/1962, em homenagem especial à Tia Ciata, que, na escola de samba da Mangueira, a ala das baianas foi criada com as caracteristicas atuais. Eram 125 baianas, coordenadas por D. Neuma.

\section{Conclusão}

0 traje de baiana foi para a Romênia como regional. E acabou virando um cartão-postal enviado ao mundo inteiro por Nic Ularu, professor de Teatro e Dança da University of South Carolina, em Columbia (EUA), e coordenador adjunto do evento romeno.

A guerra da nossa coluna continuou nas batalhas de confete do carnaval. Como desde 1990 passou a ser proibido que homens participem da ala (ainda bem!), a versão feminina desta dupla prolongou a pesquisa de campo sobre a vestimenta no carnaval carioca de 2010.

0 que se pode constatar na avenida é que o traje (bastante pesado e que deve ser apresentado em perfeita ordem e harmonia, para que a escola não perca pontos) é de folguedo. 0 curioso é que as passistas vestem a roupa de forma ritualistica, o que torna impossivel esquecer a sua origem histórica de indumentária religiosa. Muitos outros questionamentos surgiram na troca in loco com os membros da escola. ${ }^{12}$

Mas isso já é assunto para outra coluna.

\section{NOTAS}

[1] Rosane Muniz viajou com apoio do Edital de Intercâmbio e Difusão Cultural do Ministério da Cultura.

[2] Importante lembrar que o traje de baiana surgiu com os negros vindos para o Brasil com o tráfico de escravos africanos em direcão à Bahia. Apesar de ter começado com o ciclo da Guiné (durante a segunda metade do século XVI) e com o ciclo de Angola e do Congo (no século XVIII), provavelmente foi com a chegada dos daomeanos (jejês) e dos nagôs-iorubas, nos ciclos da Costa da Mina (durante os três primeiros quartos do século XVIII) e da Baía de Benin (entre 1770 e 1850), que a vestimenta da baiana veio para a terra de Cabral (VERGER, Pierre. Fluxo e refluxo do tráfico de escravos entre o golfo do Benin e a Bahia de Todos os Santos: dos séculos XVII a XIX. São Paulo: Corrupio, 1987, p. 9 [com adaptações]).

${ }^{[3]}$ Para entender, faz-se importante pensar sobre as categorias em que os têxteis podem ser divididos:

Traje eclesiástico: empregado nas mais diversas formas de ritual, tanto os ritos católicos, por exemplo, como os pagãos, das mais diversas vertentes. E designado como especial para o ato, não de uso social cotidiano, que envolve tanto o indivíduo que coordena o rito (tal como um padre) quanto aqueles que fazem parte do rito (os médiuns da Umbanda que vestem branco especialmente energizado para aquele momento, por exemplo).

Traje profissional: usado nas atividades profissionais exercidas pelos civis.

Traje dos folguedos: indumentária utilizada nas festas, nos divertimentos, nas brincadeiras de caráter popular. Entram aqui os trajes folclóricos ou das festas populares cristãs, afro-brasileiras e ibéricas.

Traje regional: caracteristico da região. Por exemplo, um traje de gaúcho que é usado para o trabalho cotidiano. Em Portugal, costuma receber o título de popular, o que achamos, no nosso caso, um pouco restritivo.

Traje popular: aquele que todos usam, no nosso contexto.

Traje típico: esta nomenclatura já foi muito utilizada, em passado mais distante, para designar a indumentária regional. Com maior aprofundamento nos estudos, típico passa a significar "característico", "que serve de tipo". E ai seu emprego passa a valer para diversas categorias de têxteis. Por exemplo, uma casula é uma veste eclesiástica típica da Igreja Católica. A roupa do maracatu é típica dos folguedos da região da Zona da Mata. A roupa branca dos médicos é uma vestimenta profissional típica. E por ai segue. Quer entrar mais nessa discussão? Acesse: <http://tramasdocafecomleite.wordpress.com/as-tramas-docafe-com-leite/as-categorias-de-texteis>.

${ }^{[4]}$ Disponivel em: <http://carmen.miranda.nom.br/grva_227.html>. Acesso em: 28 dez. 2009.

${ }^{[5]}$ Disponivel em: <http://carmen.miranda.nom.br/grva_227.html>. Acesso em: 28 dez. 2009.

${ }^{[6]}$ Disponivel em: <http://carmen.miranda.nom.br/grva_227.html>. Acesso em: 28 dez. 2009.

[7] JUNIOR, Gonçalo. Alceu Penna e as garotas do Brasil. São Paulo: Cluq, 2004, p. 68.

${ }^{[8]}$ CASTRO, Ruy. Carmen. São Paulo: Companhia das Letras, 2005.

[9] Pesquisa realizada em: <http://ibahia.globo.com/salvador459anos/interna/default.asp?modulo= 3298\&codigo=172542>. Acesso em: 15 dez. 2009.

[10] Moradora da Ilha do Governador, concedeu entrevista por telefone, direto da Alemanha, onde passava férias, em 29 dez. 2009

[11] Em entrevista na quadra da escola de samba União da Ilha do Governador, no Rio de Janeiro, em 29 dez. 2009.

${ }^{[12]}$ Acompanhe o making of da experiência no blog www.vestindoacena.com. 